\title{
PENGARUH E-COMMERCE ERA INDUSTRI 4.0 DAN KESIAPAN MENYAMBUT REVOLUSI SOCIETY 5.0
}

\author{
Abdul Majir $\mathbb{i}^{1)}$ dan Ismail Nasar $\mathbb{D}^{2)}$ \\ ${ }^{1,2}$ Pendidikan Guru Sekolah Dasar, Unika Santu Paulus Ruteng \\ ${ }^{1,2}$ Ruteng, Manggarai, kode pos 86518 \\ E-mail : abdulmajir@gmail.com ${ }^{1)}$ dan nasarismail $8 @$ gmail.com $\left.^{2}\right)$
}

\begin{abstract}
ABSTRAK
Perkembangan teknologi informasi era industri 4.0, telah mempengaruhi semua sendi kehidupan. Pertumbuhan dan perkembangan E-commerce di kalangan masyarakat telah dirasakan seluruh masyarakat. apakah ini menunjukkan kesiapan masyarakat menyambut Society 5.0? Tujuan penelitian ini adalah untuk mendeskripsikan pengaruh E-commerce pada industri 4.0 dan mendeskripsikan kesiapan dan kesesuaian industry 4.0 dengan society 5.0. Metode penelitian menggunakan penelitian kepustakaan. dengan desain deskriptif. Data diperoleh melalui jurnal, buku, dan website yang relevan. Analisis data menggunakan reduksi data (data reduction), display data dan gambaran konklusi atau verifikasi. Hasil penelitian diperoleh kesimpulan perkembangan E-commerce di era industri 4.0, dapat meningkatkan ekonomi dan perdagangan dengan memanfaatkan aplikasi E-commerce. Dimana dalam Aplikasi E-commerce terdapat kemudahan transaksi perdagangan dimana-mana (Ubiquity), bahwa teknologi internet/web tersedia kapan dan di mana saja seperti: di tempat kerja, di rumah dan di tempat lain melalui perangkat mobile. Hal ini membuat transaksi jual beli bisa terjadi di mana saja dan nyaman bagi pelanggan, biaya transaksi berkurang, informasi mudah dan murah didapat, Masyarakat sudah siap menyambut society 5.0, karena society 5.0 merupakan keseimbangan kemajuan ekonomi dengan pemecahan masalah sosial dengan memanfaatkan sistem yang menghubungkan dunia maya dan dunia nyata. perlu persiapan sumber daya manusia yang kompetitif melalui pendidikan dan latihan baik di sekolah maupun di luar sekolah.
\end{abstract}

Kata Kunci: E-Commerce, Industry 4.0, Revolusi Society 5.0

\section{PENDAHULUAN}

Teknologi informasi bukanlah sesuatu hal yang susah didapatkan saat ini, karena sudah masuk ke semua lini kehidupan masyarakat. Teknologi informasi terus berinovasi dan bertransformasi serta semakin canggih, dengan kecanggihannya bisa memberikan banyak kemudahan bagi kehidupan masyarakat. Kemudahan tersebut juga dirasakan dalam dunia ekonomi terutama dalam perdagangan. Saat ini perdagangan tidak terlepas dari teknologi informasi. Dengan adanya sinergi antara perdagangan dan teknologi informasi maka terciptalah istilah E-commerce. Di Indonesia pertumbuhan $E$ commerce sangat pesat, terutama 4 tahun terakhir, peningkatannya mencapai 500 persen, ini juga dibuktikan dari hasil riset Google dan termasuk dalam laporan E-Conomy SEA 2018 yang menunjukkan bahwa transaksi E-Commerce Indonesia mencapai US\$ 27 miliar atau setara dengan Rp 391 triliun (Rahayu, 2019).

Di sisi lain Direktur Pemberdayaan Informatika, Direktorat Jenderal Aplikasi Informatika Kementerian Kominfo (Kemenkominfo), Septriana Tangkary menyatakan bahwa pertumbuhan nilai E-commerce di Indonesia tahun 2018 mencapai 78 persen. Angka pertumbuhan tersebut merupakan yang tertinggi di dunia. Indonesia merupakan negara 10 terbesar pertumbuhan $E$ commerce dengan pertumbuhan 78 persen dan berada di peringkat pertama. Sementara Meksiko berada di peringkat kedua, dengan nilai pertumbuhan 59 persen (Zuraya.2019). Sejalan dengan pertumbuhan $E$ commerce, pada kuartal pertama tahun 2018 Indonesia sempat dihebohkan dengan munculnya istilah revolusi industry 4.0 atau industri 4.0. Hampir semua lini masyarakat dan media mainstream bertanya dan membicarakan serta memberitakan tentang industry 4.0. Tidak lama setelah itu tepatnya tanggal 20 Maret 2018 Kementerian Perindustrian menyosialisasikan bahwa kementerian nya telah merancang Making Indonesia 4.0 yaitu merupakan suatu road map yang terintegrasi untuk mengimplementasikan sejumlah strategi dalam memasuki era industri 4.0. Di Dalam sosialisasi tersebut Menteri Perindustrian Airlangga Hartarto mengatakan bahwa kita sudah memasuki industry 4.0 sejak tahun 2011, itu ditandai dengan meningkatnya konektivitas, interaksi dan batas antara manusia, mesin dan sumber daya lainnya yang semakin konvergensi melalui teknologi informasi dan komunikasi (Kementerian Perindustrian, 2018). Tidak ketinggalan juga para praktisi dan akademisi melakukan kajian-kajian dan pembicaraan ilmiah mengenai industry 4.0 yang dibandingkan dengan bidang keilmuan dan kepakaran mereka masing-masing. Sampai saat tulisan ini dibuat 
topik tentang industry 4.0 masih tetap hangat diperbincangkan dalam forum-forum resmi dan tidak resmi.

Masih hangatnya pembicaraan tentang industri 4.0, dunia dikejutkan dengan pernyataan dari Perdana Menteri Jepang Shinzo Abe pada acara pertemuan Forum Ekonomi Dunia (World Economic Forum/WEF) di Davos Swiss tanggal 23 Januari 2019. Dimana dalam pernyataannya dia mempunyai visi mengenai Masyarakat 5.0 atau Society 5.0. Dimana masyarakat 5. 0 akan dihubungkan oleh data untuk meningkatkan pertumbuhan di masa depan Haryanti, 2019).

Di Indonesia baik masyarakat umum maupun Institusi pendidikan belum semua menerapkan sistem industri 4.0 dan society 5.0 ini. Hal ini dapat dilihat dari cara berinteraksi masyarakat umum, guru dan peserta didik. Memang ada beberapa komunitas dan organisasi yang secara mandiri membahas mengenai revolusi industri 4.0 dan society 5.0, tetapi hanya cukup menjadi konsumsi pribadi. Terkait perkembangan industri 4,0 menuju society 5.0 memang perlu persiapan baik dari individu, kelompok, masyarakat umum maupun akademisi. Indonesia adalah sebuah Negara berkembang ada beberapa faktor yang sangat dibutuhkan agar dapat menjadi Negara maju, yaitu, sumber kekayaan alam (SDA) dan sumber daya manusia (SDM)

Namun sumber kekayaan alam tidak akan berguna tanpa ditunjang dari kualitas sumber daya manusianya sendiri. Salah satu cara untuk meningkatkan sumber daya manusia Indonesia adalah dengan cara meningkatkan kualitas pendidikan dan meningkatkan kualitas pelatihanpelatihan keterampilan diluar akademis agar meningkatkan kualitas keterampilan tenaga kerja dengan teknologi digital. Era Revolusi Industri 4.0 membutuhkan:

1. kemampuan untuk membaca, analisis, dan menggunakan informasi (Big Data) di dunia digital,

2. Literasi Teknologi: Memahami cara kerja mesin, aplikasi teknologi (Coding, Artificial Intelligence, \& Engineering Principles)

3. Literasi Manusia: (karakter, Komunikasi, \& Desain) (MIT, 2017 dalam Ahmadi, 2018).

\section{RUANG LINGKUP}

Berdasarkan uraian latar belakang diatas, penulis tertarik melakukan kajian dengan.

1. Masalah umum (grand theory),"Kondisi ECommerce Pada Revolusi Industri 4.0 Dan Menyambut Revolusi Society 5.0”.

2. Batasan Masalah

Untuk mengungkap teori substantif dari permasalahan, maka dibuat sub judul yaitu: a) bagaimana perkembangan E-commerce di era industri $4.0, \mathrm{~b}$ ) bagaimana kesiapan masyarakat era industri 4.0 menyambut era society 5.0 ?
3. Hasil yang direncanakan

Hasil kajian ini dapat menjelaskan secara mendalam perkembangan E-commerce di era industri 4.0, terhadap kondisi ekonomi khususnya perdagangan masyarakat, dapat menjelaskan keterkaitan industry 4.0 dengan society 5.0 dan menjelaskan hubungan industry 4.0 dengan society 5.0 terhadap peningkatan ekonomi khususnya perdagangan yang menggunakan aplikasi $E$ commerce. Juga dapat dijadikan rujukan bagi, guru, masyarakat dan pemegang kebijakan baik di tingkat daerah maupun nasional.

\section{BAHAN DAN METODE}

Untuk mengungkap teori substantif dari permasalahan tulisan ini, penulis menggunakan metode penelitian kajian pustaka (library research) yang berhadapan langsung dengan teks atau data angka, bukan dengan lapangan atau saksi mata (eyewitness), berupa kejadian, orang atau benda-benda lain. Kedua, data bersifat siap pakai (ready made), artinya peneliti tidak pergi kemana-mana, kecuali hanya berhadapan langsung dengan sumber yang sudah ada di perpustakaan. Berupa jurnal, buku, makalah dokumen dan website yang relevan dengan pokok permasalahan ( Zed, 2016)

Metode deskriptif secara etimologis deskriptif berarti menguraikan. Tidak semata-mata menguraikan melainkan juga memberikan pemahaman dan penjelasan kata-kata, atau tulisan dari orang-orang dan perilaku yang diamati. Penulis mendeskripsikan kondisi $E$ Commerce era Industri 4.0, keselarasan industry 4.0 dengan society 5.0 terhadap perkembangan E-commerce. Selanjutnya mengkritisi, memberikan gagasan kritis dalam hasil penelitian sebelumnya dengan menghadirkan temuan baru dalam mengelaborasikan pemikiranpemikiran yang berbeda(Hendarsyah. 2012).

\section{PEMBAHASAN}

Pada bagian ini akan dibahas tentang E-commerce, Industri 4.0, Society 5.0.

\subsection{E-commerce}

E-commerce adalah penggunaan internet, web dan aplikasi untuk transaksi bisnis secara digital antara perusahaan dan individu (Laudon, 2014). Sedangkan menurut (Turban dkk, 2015), E-commerce adalah penggunaan internet untuk membeli, menjual, mengangkut, atau memperdagangkan data, barang atau jasa. Kemudian dalam tulisan (Syahrul dkk, 2011) Ecommerce memiliki arti yang luas dan sempit. Arti luas, adalah pembelian atau penjualan barang antara bisnis, rumah tangga, individu, pemerintah dan organisasi publik dan swasta lainnya melalui jaringan komputer. Sedangkan arti sempit dari E-commerce perdagangan yang menggunakan jaringan internet (Hendarsyah, 2015). 
Berdasarkan pengertian di atas, maka dapat ditarik kesimpulan bahwa E-commerce adalah kegiatan perdagangan baik jasa maupun barang lakukan secara perorangan, kelompok, swasta ataupun pemerintah dalam transaksi menggunakan jaringan internet. Adapun kerangka utama dari E- commerce terdiri dari people (penjual, pembeli, perantara, sistem informasi), public policy (kebijakan dan peraturan publik seperti pajak dan regulasi), marketing and advertising (pemasaran dan periklanan seperti promosi, konten web, target pemasaran dan lainnya), support services (layanan pendukung seperti logistik, pembayaran, keamanan sistem dan jaringan dan lainnya), business partnerships (kemitraan bisnis seperti program afiliasi, pertukaran dan lainnya) (Turban dkk, 2015)

Perkembangan E-commerce, hingga saat ini $E$ commerce ditransformasikan ke jejaring sosial yang bisa diakses secara luas oleh perangkat seluler konsumen seperti smartphone dan komputer tablet. Pemasaran ditransformasikan melalui jejaring sosial, mesin pencari, web, platform ponsel dan email. Menurut (Laudon dkk, 2014) bahwa di dalam teknologi E-commerce terdapat ada istilah Ubiquity, yang diartikan dimana-mana, artinya bahwa teknologi internet/web tersedia kapan dan di mana saja seperti: di tempat kerja, di rumah dan di tempat lain melalui perangkat mobile. Hal ini membuat transaksi jual beli bisa terjadi di mana saja selama kenyamanan pelanggan dapat ditingkatkan dan biaya transaksi berkurang. Kondisi ini membuat perdagangan tanpa batas budaya dan Negara (global reach). Sehingga banyak informasi menjadi murah dan akurat.

Uraian di atas dapat disimpulkan bahwa aplikasi $E$ commerce sangat membantu masyarakat baik bagi produsen maupun konsumen.

\subsection{Industri 4.0}

Istilah industry 4.0 mulai dikenal publik pada tahun 2011, oleh asosiasi perwakilan bisnis, politik dan akademisi Jerman yang menggunakan pendekatan industry 4.0. dengan sebutan zaman cyber physical systems atau otomatisasi cerdas (Bahrin dkk, 2016). Hal senada disampaikan (Rojko, 2017) mengatakan bahwa konsep dasar industry 4.0 pertama kali di presentasi di pameran Hannover pada tahun 2011. Sejak diperkenalkan industry 4.0 di Jerman, industry 4.0 menjadi topik diskusi umum dalam komunitas peneliti, akademik dan industri di berbagai kesempatan. selanjutnya, industri 4.0 secara resmi diumumkan pada 2013 sebagai inisiatif strategis Jerman untuk mengambil peran perintis dalam industri yang saat ini berevolusi sektor manufaktur (Mestika, 2016).

Menurut (Bahrain, 2016) teknologi yang terkait dengan industri 4.0 yaitu: The Internet of Things (IoT), berfungsi untuk menghubungkan semua perangkat komputasi menggunakan teknologi tertentu. Dimana berkomunikasi dan berinteraksi satu sama lain dengan pengontrolan yang terpusat, seperti mesin, produk dan manusia. Hal ini dapat mengurangi waktu pengaturan alat dan meningkatkan kualitas produk. Robots, lebih mandiri, fleksibel dan kooperatif, mereka akan berinteraksi satu sama lain dan dapat bekerja dengan aman bersama manusia, kemudian belajar dari mereka. Robot lebih murah biayanya dan memiliki jangkauan kemampuan yang lebih besar.

Setelah Jerman, Amerika pun menggerakan Smart Manufacturing Leadership Coalition (MLC), sebuah organisasi nirlaba yang terdiri dari produsen, pemasok, perusahaan, teknologi, lembaga pemerintah, universitas dan laboratorium yang memiliki tujuan untuk memajukan cara berpikir dibalik Revolusi Industri 4.0 (Yenny Puspita dkk, 2020). Revolusi Industri 4.0 ini perkembangan internet sangat signifikan, selain Internet of Thing (IoT), muncul big data, percetakan 3D, kecerdasan buatan (Artificial Intelligence), kendaraan tanpa pengemudi, rekayasa genetika, robot dan mesin pintar.

Berdasarkan uraian tersebut, maka dapat disimpulkan revolusi Industri 4.0 lebih mengandalkan perkembangan teknologi lebih diutamakan, dari pada peran tenaga manusia.

\subsection{Society 5.0}

Awal Januari 2019 lalu, muncul gagasan baru dari Negara Jepang yaitu society 5.0 disampaikan dalam Forum Ekonomi di Davos, Swiss (Hendarsyah, 2016). Gagasan ini sebagai respons revolusi Industri 4.0 yang di gagas oleh Negara Jerman (Fukuyama, 2018). Society 5.0 menawarkan kegiatan masyarakat yang berpusat pada manusia. Adanya keseimbangan antara kemajuan ekonomi dengan pemecahan masalah sosial dengan memanfaatkan sistem yang menghubungkan dunia maya dan dunia nyata. Dimana society 5.0 modal bukan hal utama, tetapi data yang menghubungkan dan menggerakkan segalanya untuk mengatasi kesenjangan antara yang kaya dan yang kurang beruntung termasuk pada layanan kesehatan dan pendidikan yang berada di masyarakat dari perkotaan sampai ke pedesaan. Jika industry 4.0 memungkinkan kita untuk mengakses juga membagikan informasi di internet sedangkan Society 5.0 adalah era di mana semua teknologi adalah bagian dari manusia itu sendiri. Internet bukan hanya sebagai informasi melainkan untuk menjalani kehidupan. Sehingga perkembangan teknologi dapat meminimalisasi adanya kesenjangan pada manusia dan masalah ekonomi pada kemudian hari.

Konsep Society 5.0 diadopsi Pemerintah Jepang sebagai antisipasi terhadap tren global sebagai akibat dari munculnya revolusi Industri 4.0. Society 5.0 merupakan jawaban atas tantangan yang muncul akibat era revolusi Industri 4.0 yang dibarengi disrupsi yang ditandai dunia yang penuh gejolak, ketidakpastian, kompleksitas, dan ambiguitas. Society 5.0, sebuah masa di mana masyarakat berpusat pada manusia yang menyeimbangkan kemajuan ekonomi dengan 
penyelesaian masalah sosial oleh sistem yang mengintegrasikan ruang dunia maya dan ruang fisik. Society 5.0 akan menyeimbangkan pembangunan ekonomi dan menyelesaikan masalah sosial. Kompetensi yang dibutuhkan Society 5.0 adalah kemampuan memecahkan masalah kompleks, berpikir kritis, dan kreativitas.

Dalam Society 5.0, nilai baru yang diciptakan melalui inovasi akan menghilangkan kesenjangan regional, usia, jenis kelamin dan bahasa dan memungkinkan penyediaan produk dan layanan yang disesuaikan dengan baik untuk beragam kebutuhan individu dan kelompok. Dengan cara ini, memungkinkan untuk mencapai masyarakat yang dapat meningkatkan pembangunan ekonomi dan menemukan solusi masalah sosial (Nakanishi dan Kitano, 2018).

Berdasarkan uraian di atas maka revolusi industri lahir melalui tahapan-tahapan masyarakat yang saling berkesinambungan. Sedangkan industri 4.0 dan society 5.0 muncul beriringan dimana industri 4.0 lebih fokus kepada industri terutama bidang manufaktur seperti tekstil, otomotif, makanan dan minuman, elektronik, biokimia dan sebagainya. Sedangkan society 5.0 masih berupa visi dan fokus kepada manusia yang mengharuskan penguasaan kemampuan memecahkan masalah kompleks, berpikir kritis, dan kreativitas. Ketiganya menjadi tanggung jawab dunia pendidikan dengan konstruksi Masyarakat 5.0 (Auliani \& Annisa., 2019).

Dalam Society 5.0 digambarkan bahwa setiap kegiatan yang dilakukan manusia sangat bergantung kepada teknologi. Teknologi sudah menjadi kebutuhan dasar dalam sendi-sendi kehidupan manusia, semua terintegrasi dengan smartphone. Dalam transaksi bisnis masyarakat juga sudah tergantung dengan teknologi sehingga transaksi bisnis tidak menggunakan transaksi tradisional. Dengan hal demikian maka E-commerce akan menjadi primadona dalam transaksi bisnis, sehingga prospeknya semakin cerah. Ini juga merupakan salah satu pendongkrak munculnya perusahaan-perusahaan start-up baru untuk memenuhi kebutuhan masyarakat secara luas. Sebenarnya, konsep revolusi industry 4.0 dan society 5.0 tidak memiliki perbedaan yang signifikan. Dimana revolusi industri 4.0 menggunakan kecerdasan buatan (artificial intelligence) sedangkan society 5.0 memfokuskan kepada komponen

manusianya. Konsep society 5.0 ini, menjadi inovasi baru dari society 1.0 sampai society 4.0 dalam sejarah peradaban manusia. Industry 4.0 yang kita alami saat ini, manusia dalam kehidupan sehari menggunakan komputer dengan jaringan internet. Jika industry 4.0 memungkinkan kita untuk mengakses juga membagikan informasi di internet. Society 5.0 adalah era di mana semua teknologi adalah bagian dari manusia itu sendiri. Internet bukan hanya sebagai informasi melainkan untuk menjalani kehidupan. Sehingga perkembangan teknologi dapat meminimalisasi adanya kesenjangan pada manusia dan masalah ekonomi pada kemudian hari (Cabinet Office Japan Government., 2019).

Sayangnya Institusi pendidikan di Indonesia pun belum semua menerapkan sistem industry 4.0 dan mempersiapkan diri menyambut society 5.0 ini. Hal dapat diamati mulai dari sistem pendidikan sampai cara berinteraksi pendidik dengan peserta didik. Walaupun ada komunitas dan organisasi itu hanya sebagian kecil membahas mengenai industri 4.0 dan society 5.0, itu pun hanya menjadi konsumsi pribadi bukan menjadi konsumsi publik. Padahal industry 4,0 menuju society 5.0 perlu persiapan baik secara individual, masyarakat maupun akademisi. Pendidikan memiliki peranan penting dalam hal ini. Sebab menyambut revolusi society 5.0 dibutuhkan manusia berpikir yang lebih kritis.

Salah satu cara untuk meningkatkan sumber daya manusia Indonesia adalah dengan cara meningkatkan kualitas pendidikan dan pelatihan-pelatihan keterampilan di luar akademik. Salah satu yang menjadi kelemahan pendidikan di Indonesia adalah bentuk kurikulum nya. Kurikulum terlalu banyak memaksa para pelajar untuk menghafal materi bahkan hanya dengan penjelasan dan membayangkan, sedangkan praktik masih terlalu sedikit. Industri 4.0 sebagian besar membutuhkan SDM yang menguasai teknologi untuk menjual produk mereka secara online, semakin pentingnya kecakapan sosial (social skills) dalam bekerja (Xu, Li Da dkk, 2018).

Sedangkan modal dasar untuk berkiprah di masyarakat industry 4.0 menyambut society 5.0 yaitu:

1. Literasi Data: Kemampuan untuk membaca, analisis, dan menggunakan informasi (Big Data) di dunia digital,

2. Literasi Teknologi: Memahami cara kerja mesin, aplikasi teknologi (Coding, Artificial Intelligence, \& Engineering Principles),

3. (3) Literasi Manusia: Humanities, Komunikasi, \& Desain ( Aoun, MIT, 2017 dalam Ahmad, I, 2018)

Berdasarkan uraian di atas, maka dapat disimpulkan pendidikan pada semua jenjang perlu pengenalan dunia nyata tidak hanya sebatas lingkungan sekitar. Tetapi lingkungan universal yang bisa dijelajahi menggunakan fasilitas laman daring. Hal ini bertujuan untuk meningkatkan kualitas diri peserta didik sesuai tuntutan masyarakat global. Peserta didik juga dituntut bisa memanfaatkan telepon genggam, tablet, atau laptop yang ter-koneksi internet, sebagai bagian atau sumber pembelajaran. Sebab sebagian bahan ajar atau materi diskusi diperoleh dari berbagai situs-situs pendidikan Ruang guru, Wikipedia, dan lainnya. Pelaksanaan Pendidikan seperti ini minimal memberikan bekal bagi peserta didik untuk selalu siap menghadapi tantangan dan perkembangan zaman. Di era Revolusi Industry 4.0 menuju Society 5.0 saat ini, terjadi di bidang pendidikan menjadi lebih ketat, maka dibutuhkan tenaga yang mampu berkompetisi yang sesuai dengan kebutuhan masyarakat. 
Menurut (Prima, E., 2019). Visi Jepang dalam Society 5.0 yaitu integrasi ruang maya dan fisik. Retrieved from Tempo Perkembangan teknologi informasi saat ini terjadi di seluruh bidang, teknologi dengan pendekatan yang menggabungkan digital secara fundamental. Era industry 4.0 ini Negara Indonesia masih terdapat beberapa tantangan seperti kurangnya tenaga keterampilan, belum memahami penggunaan teknologi komunikasi, masih memandang bahwa teknologi banyak dampak negative dalam kehidupan. Padahal teknologi berdampak positif tergantung bagaimana individu dalam meminimalisasi risiko dan peluang yang muncul. Revolusi industri 4.0 yang dinilai berpotensi dalam mendegradasi peran manusia membuat Jepang melahirkan sebuah konsep yaitu Society 5.0. Melalui konsep ini diharapkan membuat kecerdasan buatan akan mentransformasikan big data yang dikumpulkan melalui internet pada segala bidang kehidupan menjadi suatu kearifan yang baru, dengan harapan untuk meningkatkan kemampuan manusia dalam membuka peluang-peluang bagi manusia (Santoso, 2019).

Perbandingan dari kedua konsep ini yaitu pada industry 4.0, masyarakat mencari, mengutip, dan menganalisis data atau informasi dengan mengakses layanan cloud melalui internet. Sedangkan, pada Society 5.0 sejumlah besar informasi dari sensor di ruang fisik terakumulasi di dunia maya dan dianalisis oleh kecerdasan buatan, dan hasilnya diumpan kembali ke manusia dalam ruang fisik dalam berbagai bentuk. Dampak dari revolusi industry 4.0 dan Society 5.0 membuat kesempatan baru untuk Indonesia. Menurut Menteri Perindustrian Airlangga Hartanto, revolusi industry 4.0 justru memberi kesempatan bagi Indonesia untuk berinovasi

Konsep Society 5.0 diadopsi Pemerintah Jepang sebagai antisipasi terhadap tren global sebagai akibat dari munculnya Revolusi Industry 4.0. Society 5.0 adalah hal alami yang pasti terjadi akibat munculnya Revolusi Industri 4.0. Revolusi Industri 4.0 telah melahirkan berbagai inovasi dalam dunia industri dan juga masyarakat secara umum. Society 5.0 merupakan jawaban atas tantangan yang muncul akibat era Revolusi Industry 4.0 yang dibarengi disrupsi yang ditandai dunia yang penuh gejolak, ketidakpastian, kompleksitas, dan ambiguitas.

Society 5.0 adalah masyarakat yang dapat menyelesaikan berbagai tantangan dan permasalahan sosial dengan memanfaatkan berbagai inovasi yang lahir di era Revolusi industry 4.0 seperti Internet on Things (internet untuk segala sesuatu), Artificial Intelligence (kecerdasan buatan), Big Data (data dalam jumlah besar), dan robot untuk meningkatkan kualitas hidup manusia. Society 5.0, sebuah masa di mana masyarakat berpusat pada manusia yang menyeimbangkan kemajuan ekonomi dengan penyelesaian masalah sosial oleh sistem yang mengintegrasikan ruang dunia maya dan ruang fisik.
Society 5.0 akan menyeimbangkan pembangunan ekonomi dan menyelesaikan masalah sosial. Sedangkan Society 5.0 menuntut setiap individu memiliki tiga kemampuan utama yang yaitu kemampuan memecahkan masalah kompleks, berpikir kritis, dan kreativitas.

Penguasaan ketiga kemampuan utama tersebut menjadi tanggung jawab dunia pendidikan. Anak-anak yang sekarang duduk di bangku sekolah merupakan pemilik masa depan tersebut. Masa depan dengan konstruksi Masyarakat 5.0, tetapi sekaligus berada pada era penuh gejolak, tidak pasti, rumit, dan serba kabur. Tak ayal lagi, para pemegang masa depan tersebut tidak cukup dibekali dengan timbunan ilmu pengetahuan, tetapi juga cara berpikir.

Oleh karena itu dimulai dari sekarang diperkenalkan cara berpikir yang analitis, kritis, dan kreatif. Cara berpikir itulah yang disebut cara berpikir tingkat tinggi (HOTS: Higher Order Thinking Skills). Berpikir HOTS bukanlah berpikir biasa-biasa saja, tetapi berpikir secara kompleks, berjenjang, dan sistematis. Kemampuan HOTS ini, dapat dilatih dalam proses pembelajaran di kelas. Dengan cara memberi ruang kepada peserta didik untuk menemukan konsep pengetahuan berbasis aktivitas agar peserta didik terdorong untuk membangun kreativitas dan berpikir kritis. Para guru boleh memilih aneka model pembelajaran, seperti discovery learning, project based learning, problem based learning, dan inquiry learning. Cara model mengajari seperti diyakini mampu mengembangkan nalar kritis anak didik.

Pembiasaan HOTS bagi peserta didik akan merasakan langsung situasi dunia nyata. Dengan mengenali dunia nyata, para peserta didik akan mengenal kompleksitas permasalahan yang ada di sekitar mereka. Seperti masalah lingkungan hidup, kesehatan dan ruang angkasa. pemanfaatan ilmu pengetahuan dan teknologi dalam berbagai aspek kehidupan. Dalam hal ini guru berperan sebagai fasilitator bagi peserta didik untuk menawarkan arah dalam menemukan solusinya. Harapannya, mampu berinovasi yang memiliki nilai kebaruan sesuai konteks, situasi yang baru pula bukan copy paste. Itulah yang disebut kreativitas dan inovasi.

\section{KESIMPULAN}

Perkembangan E-commerce di era industry 4.0, telah mengubah cara hidup masyarakat dan industri, sehingga membawa pengaruh yang besar terhadap kemajuan ecommerce. Sebab di dalam teknologi E-commerce terdapat kemudahan dengan istilah "Ubiquity", yang diartikan dimana-mana, artinya bahwa teknologi internet/web tersedia kapan dan di mana saja seperti: di tempat kerja, di rumah dan di tempat lain melalui perangkat mobile. Hal ini membuat transaksi jual beli bisa terjadi di mana saja dan nyaman bagi pelanggan, biaya transaksi berkurang, informasi mudah dan murah didapat.

Masyarakat sudah siap menyambut society 5.0, karena society 5.0 merupakan keseimbangan kemajuan 
ekonomi dengan pemecahan masalah sosial dengan memanfaatkan sistem yang menghubungkan dunia maya dan dunia nyata. Dimana society 5.0 modal bukan hal utama, tetapi data yang menghubungkan dan menggerakkan segalanya untuk mengatasi kesenjangan antara yang kaya dan yang kurang beruntung termasuk pada layanan kesehatan dan pendidikan yang berada di masyarakat dari perkotaan sampai ke pedesaan. Jika industry 4.0 memungkinkan kita untuk mengakses juga membagikan informasi di internet sedangkan Society 5.0 adalah era di mana semua teknologi adalah bagian dari manusia itu sendiri. Internet bukan hanya sebagai informasi melainkan untuk menjalani kehidupan. Salah satu cara untuk meningkatkan sumber daya manusia yang kompetitif dengan cara meningkatkan kualitas pendidikan dan latihan sejak sedini mungkin. Revolusi industry 4.0 adalah proses lanjutan perubahan Teknologi berdampak positif. Dengan memiliki kompetensi utama yaitu berpikir analitis, kritis, dan kreatif mampu memecahkan masalah sosial yang terjadi baik di tingkat lokal maupun masalah dunia internasional.

\section{SARAN}

Pemerintah pusat dan daerah agar membuat regulasi yang tepat untuk melindungi konsumen dan produsen dalam melakukan transaksi elektronik.

Para pendidik agar berani melakukan revolusi pembelajaran lebih banyak secara praktik terutama pemanfaatan aplikasi E-commerce tidak hanya sekolah kejuruan

Untuk peneliti berikutnya, dapat melakukan penelitian serupa dengan tema yang berbeda demi kesempurnaan penelitian ini. Hasil penelitian dapat dijadikan teori dasar dalam penelitian selanjutnya.

\section{DAFTAR PUSTAKA}

Ahmad, I. (2018). Pendidikan Tinggi “4.0” Yang Mampu Meningkatkan Daya Saing Bangsa. Direktur Jenderal Pembelajaran dan Kemahasiswaan, Kementerian Riset, Teknologi, Dan Pendidikan Tinggi. Makassar, 16 Februari 2018. Bahan Presentasi.

Auliani, \& Annisa.P (2019). AI, IoT, dan Tantangan Sektor Logistik di Era Revolusi Industri 4.0. Kompas.com, 11 Februari 2019. Diakses dari: https: // ekonomi.kompas. com/ read/ 2019 /02/11/114445026/ai-iot-dan-tantangan-sektorlogistik-di-era-revolusi-industri-40?page=all, tanggal 22 Agustus 2019.

Auliani, Palupi Annisa. (2019a). Optimalisasi Perusahaan melalui Layanan "Shared Service" di Industri 4.0. Kompas.com,23 Mei 2019. Diakses dari: https://money.kompas.com/read/2019/05/23/ 132110826/optimalisasi-perusahaan-melaluilayanan-shared-service-di-industri-40?page=all, tanggal 28 Agustus 2019.

Bahrin, Mohd Aiman Kamarul et al. (2016). "Industry
4.0: A Review On Industrial Automation And Robotic", Jurnal Teknologi (Sciences \& Engineering) UTM 78 (6-13), 137-143. https://doi.org/10.11113/jt.v78.9285

Cabinet Office Japan Government. (2019). Society 5.0.Diakses dari:https://www8.cao.go.jp/cstp/english/ society5_0/index. html, tanggal 6 Agustus

Fukuyama, Mayumi. (2018). Society 5.0: Aiming for a New Human-Centered Society. Japan Economy Foundation Journal-Japan SPOTLIGHT. https://www.

jef.or.jp/journal/pdf/220th_Special_Article_02.pdf. diakses tanggal 27 Agustus 2019.

Haryanti, Rosiana. (2019). Society 5.0: Solusi Jepang Atasi Defisit Penduduk dan Infrastruktur. Kompas. com, 28 Januari 2019.Diakses dari: https:// properti. kompas. com/ $\mathrm{read} / 2019 / 01 / 28 / 115422021 /$ society-50-solusijepang-atasi-defisit-penduduk-daninfrastruktur?page=all, tanggal 6 Agustus 2019.

Hendarsyah, Decky. (2012). "Keamanan Layanan Internet Banking Dalam Transaksi Perbankan: IQTISHADUNA: Jurnal Ilmiah Ekonomi Kita 1 (1), 12-33.

Hendarsyah, Decky. (2015). Bisnis Toko Online:. IQTISHADUNA: Jurnal Ilmiah Ekonomi Kita 4 (1), 1-14.

Hendarsyah, Decky. (2016). Penggunaan Uang Elektronik Dan Uang Virtual Sebagai Pengganti Uang Tunai Di Indonesia. IQTISHADUNA: Jurnal Ilmiah Ekonomi Kita 5 (1), 1-15.

Kementerian Perindustrian. (2018). Making Indonesia 4.0:Strategi RI Masuki Revolusi Industri Ke-4. Diakses dari: https:// kemenperin. go. Id /artikel /18967/Making-Indonesia-4.0:-Strategi-RI-

Masuki-Revolusi-Industri-Ke-4, tanggal 30 Juli 2019.

Laudon, Kenneth C. and Carol Guercio Traver. (2014). E-Commerce: Business, Technology \& Society 10th edition. New Jersey: Pearson.

Mestika, Zed. (2016). Metode Penelitian Kepustakaan. Jakarta: Yayasan Obor Indonesia

Nakanishi, Hiroaki and Hiroaki Kitano. (2018). Society 5.0 Co-Creating The Future: Policy Proposals Industrial Technology, Keidanren (Japan BusinessFederation)

Prima, E. (2019). Mengenal Visi Jepang Society 5.0: Integrasi Ruang Maya dan Fisik. Retrieved from Tekno Tempo

Santoso, K.A. (2019). Pendidikan Untuk Menyambut Society 5.0. Retrieved from Tekno Tempo Syahrul, Mesut and Cüneyt Kılıç. 2011. "ECommerce As An Alternative Strategy In Recovery From The Recession". $7^{\text {th }}$ International Strategic Management Conference, Procedia Social and Behavioral 
Sciences 24, 247-259. Elsevier.

Rahayu, Ning. (2019). Pertumbuhan E-Commerce Pesat di Indonesia. Warta Ekonomi Online, 19 Februari 2019. Diakses dari: https: // www. wartaekonomi.co.id/read216302/pertumbuhan-ecommerce- pesat-di-indonesia.html, tanggal 21 Agustus 2019.

Rojko, Andreja. 2017. "Industry 4.0 Concept: Background and Overview". International Journal of Interactive Mobile Technologies (iJIM) 11 (5), 77-90. https://doi.org/10.3991/ijim.v11i5.7072.

Turban, Efraim et al. 2015. Electronic Commerce: A Managerial and Social Networks Perspective Eighth Edition. Switzerland: Springer.

Yenny, Fitriani, Astuti, Novianti. (2020). Prosiding Seminar Nasional Pendidikan, Program Pascasarjana Universitas Pgri Palembang 10
Januari 2020

Xu, Li Da dkkl. (2018). Industry 4.0: State Of The Art And Future Trends. International Journal of Production Research 56 (8), 2941-2962. https://doi.org/10.1080/00207543.2018.1444806

Zuraya, Nidia. (2019). Pertumbuhan E-Commerce Indonesia Tertinggi di Dunia. Republika

Online, 27 Februari 2019. Diakses dari:https: //www.republika.co.id/berita/ekonomi/korporasi/pn krfg383/pertumb uhan-emecommerceemindonesia-tertinggi-di-dunia, tanggal 21 Agustus 2019 